\title{
Immunoglobulin Treatment Reduces Atherosclerosis in apo E Knockout Mice
}

\author{
Antonino Nicoletti, ${ }^{\star \ddagger}$ Srini Kaveri, ${ }^{\circ}$ Giuseppina Caligiuri, ${ }^{\star}$ Jean Bariéty, ${ }^{\ddagger}$ and Göran K. Hansson* \\ *Center for Molecular Medicine, Karolinska Institute, S-17176 Stockholm, Sweden; and ${ }^{\ddagger}$ INSERM U430, Hôpital Broussais, Paris, France
}

\begin{abstract}
Atherosclerosis is associated with immune activation. $\mathrm{T}$ cells and macrophages infiltrate atherosclerotic plaques and disease progression is associated with formation of autoantibodies to oxidized lipoproteins. In the apo E knockout mouse, a genetic model of cholesterol-induced atherosclerosis, congenital deficiency of macrophages, lymphocytes, or interferon- $\gamma$ receptors result in reduced lesion formation. We have now evaluated whether immune modulation in the adult animal affects disease development. Injections of 7-wk-old male apo E knockout mice with polyclonal immunoglobulin preparations (ivIg) during a 5-d period reduced fatty streak formation over a 2-mo period on cholesterol diet by $35 \%$. Fibrofatty lesions induced by diet treatment for 4 mo were reduced by $50 \%$ in mice receiving ivIg after 2 mo on the diet. ivIg treatment also reduced IgM antibodies to oxidized LDL and led to inactivation of spleen and lymph node $T$ cells. These data indicate that ivIg inhibits atherosclerosis, that it is effective both during the fatty streak and plaque phases, and that it may act by modulating $T$ cell activity and/or antibody production. Therefore, immunomodulation may be an effective way to prevent and/or treat atherosclerosis. (J. Clin. Invest. 1998. 102:910-918.) Key words: antibody • atherosclerosis $\bullet$ immunoglobulin $\bullet T$ cells
\end{abstract}

\section{Introduction}

Atherosclerosis is associated with an activation of the immune system. Atherosclerotic plaques are infiltrated by macrophages and T lymphocytes, some of which immunospecifically recognize oxidized LDL (oxLDL) ${ }^{1}(1)$, which also accumulate in plaques. Autoantibodies to oxLDL are also found in atherosclerotic plaques $(2,3)$ together with activated components of the complement cascade $(4,5)$. In fact, the titer of auto-antioxLDL may correlate with progression of atherosclerosis in humans (6). However, it is still unclear to what extent interference with immunopathologic mechanisms may modulate the progression of the disease.

Address correspondence to Dr. Göran K. Hansson, Center for Molecular Medicine L8:03, Karolinska Hospital, S-17176 Stockholm, Sweden. FAX: 46-8-313147; E-mail: Goran.Hansson@cmm.ki.se

Received for publication 24 February 1998 and accepted in revised form 9 July 1998.

1. Abbreviations used in this paper: Con A, Concanavalin A; ivIg, intravenous Ig preparation; KO, knockout; MDA, malondialdehyde; oxLDL, oxidized LDL.

J. Clin. Invest.

(C) The American Society for Clinical Investigation, Inc. 0021-9738/98/09/0910/09 \$2.00

Volume 102, Number 5, September 1998, 910-918

http://www.jci.org
The recently developed apolipoprotein E knockout (apo E $\mathrm{KO}$ ) mouse offers new opportunities to study pathogenetic mechanisms. These mice develop atherosclerotic lesions similar to those found in humans within weeks after birth (7). Although the atherosclerotic disease of these mice is based solely on a genetic disturbance of lipid metabolism, activated macrophages and $\mathrm{CD}^{+} \mathrm{T}$ cells infiltrate their lesions from the start (8) and autoantibodies to oxLDL similar to those found in humans appear in their peripheral blood (9). This suggests that the immune response is directly linked to the metabolic abnormality and that it is central to the pathogenesis of the disease. Congenital deficiency of macrophages, lymphocytes, and the Th1 effector pathway, by cross-breeding apo E KO mice with op/op mutant mice (10), T and B cell-deficient RAG-1 $\mathrm{KO}$ mice (11), and interferon- $\gamma$ receptor $\mathrm{KO}$ mice (12), respectively, have resulted in reduction of lesions by 80,40 , and $60 \%$, respectively. These results underline the importance of immune mechanisms in atherogenesis, but since they are based on genetic defects they do not clarify whether immunomodulation may be used to treat or prevent atherosclerosis.

Intravenous immunoglobulins (ivIg) are preparations of normal polyspecific IgG obtained from large pools of plasma from healthy donors. In addition to its use as substitution therapy for primary and secondary antibody deficiencies, ivIg is used increasingly in patients with autoimmune and systemic inflammatory diseases $(13,14)$. The mode of action of ivIg is still unclear and may involve both Fc- and $\mathrm{V}$ region-dependent mechanisms (for review see reference 15). Fc fragments of Ig may block Fc receptors on phagocytic cells of the reticuloendothelial system, inhibit antibody synthesis by B cells, modulate suppressor and helper functions of $\mathrm{T}$ cells, affect the production of cytokines by monocytes/macrophages, and interfere with complement-mediated tissue damage. ivIg have also been shown to contain antibodies that recognize idiotypic determinants on autoantibodies. Modulation of $\mathrm{B}$ and $\mathrm{T}$ cell function including cytokine production has been observed during ivIg treatment in rodent models of autoimmune diseases (16-19).

Several of these mechanisms could conceivably be beneficial in atherosclerosis. For instance, ivIg could regulate the production of autoantibodies against oxLDL, modulate $\mathrm{T}$ cell functions in plaques, control complement activation, and affect phagocytosis and cytokine production by macrophages. In the present communication, we show that ivIg treatment of apo E $\mathrm{KO}$ mice inhibits the progression of atherosclerosis.

\section{Methods}

Biological preparations/immunogens/immunomodulators. ivIg (San$\operatorname{doglobulin}^{\circledR}$ ) was a gift of the Central Laboratory of the Swiss Red Cross (Bern, Switzerland). When reconstituted for therapeutic use, Sandoglobulin ${ }^{\circledR}$ contains $50 \mathrm{mg} / \mathrm{ml}$ of IgG, $25-35 \mathrm{mg} / \mathrm{ml}$ sucrose, $6-10$ $\mathrm{mg} / \mathrm{ml}$ glucose, and 40-100 mM NaCl (osmolality 515 mosmol). For this study, a stock solution of $100 \mathrm{mg} / \mathrm{ml}(0.6 \mathrm{mM})$ of ivIg was prepared in serum-free RPMI containing L-glutamine, penicillin $50 \mathrm{U} / \mathrm{ml}$, and streptomycin $50 \mathrm{mg} / \mathrm{ml}$. The ivIg solution was dialyzed overnight against a DME medium to remove the stabilizing agents of the Sandoglobulin ${ }^{\circledR}$ preparation. The final osmolality of the medium was 
Table I. Experimental Design

\begin{tabular}{|c|c|c|c|c|c|}
\hline \multirow[b]{2}{*}{ Groups } & \multirow[b]{2}{*}{$n$} & \multicolumn{4}{|c|}{ Months } \\
\hline & & 0 & 1 & 2 & 4 \\
\hline \multicolumn{6}{|l|}{ Experiment 1} \\
\hline iv $\operatorname{Ig}[0-1]$ & 3 & 5 i.p. injections & Killed & & \\
\hline $\mathrm{HSA}[0-1]$ & 2 & 5 i.p. injections & Killed & & \\
\hline ivIg[0-2] & 5 & 5 i.p. injections & & Killed & \\
\hline $\mathrm{HSA}[0-2]$ & 5 & 5 i.p. injections & & Killed & \\
\hline \multicolumn{6}{|l|}{ Experiment 2} \\
\hline ivIg[0-4] & 5 & 5 i.p. injections & & & Killed \\
\hline HSA $[0-4]$ & 5 & 5 i.p. injections & & & Killed \\
\hline ivIg[2-4] & 5 & & & 5 i.p. injections & Killed \\
\hline HSA[2-4] & 5 & & & 5 i.p. injections & Killed \\
\hline $\operatorname{ivIg}[0 / 2-4]$ & 4 & 5 i.p. injections & & 1 i.p. injection & Killed \\
\hline $\mathrm{HSA}[0 / 2-4]$ & 4 & 5 i.p. injections & & 1 i.p. injection & Killed \\
\hline Untreated[0/0-4] & 4 & & & & Killed \\
\hline
\end{tabular}

For abbreviations, please see text.

270 mosmol. As a control preparation, we used HSA (Amersham Pharmacia Biotech, Uppsala, Sweden) made as fraction V of human serum pooled from multiple donors and containing $10 \mathrm{mg} / \mathrm{ml} \mathrm{HSA}$ dissolved in the above medium.

Experimental protocol. apo E KO mice were obtained from The Jackson Laboratory (Bar Harbor, ME). This strain was developed on a 129/J background and had been backcrossed six times to C57BL/6 J mice (20). At 5-7 wk of age, male apo E KO mice were put on a "Western" diet (see below) and injected with ivIg or HSA as described in Table I. Two series of experiments were carried out. In the first one, the effect of ivIg on fatty streak development was assessed 1 and 2 mo after five ivIg injections. In the second series of experiments, the effect on the development of fibrofatty atherosclerotic plaques was analyzed after 4 mo of diet. The mice in the experimental groups received an intraperitoneal injection of $10 \mathrm{mg}$ ivIg daily over a 5 -d period. In the control groups, the mice received $10 \mathrm{mg}$ HSA instead of ivIg. In the second series of experiments, a control group was added that was left completely untouched except for diet treatment. The animal experiments were approved by the regional ethical board.

Diet. The mice were placed on a Western diet (AB AnalyCen, Liköping, Sweden) that contained $16.7 \%$ protein and $21.2 \%$ fats. It was based on corn starch, casein, glucose, saccharose, cocoa butter, cellulose, minerals, cholesterol, and a vitamin mix. The cholesterol content was $0.15 \%$ and the energy content was $16.4 \mathrm{MJ} / \mathrm{kg}$.

Tissue processing. Mice were killed by exsanguination under carbon dioxide anesthesia. The blood was collected and allowed to clot. Serum was separated by centrifugation and stored at $-20^{\circ} \mathrm{C}$. The cholesterol concentration was assessed using a Unimate kit (Hoffman-La Roche, Basel, Switzerland) and a Cobas Mira analytical system (Hoffman-La Roche). The vasculature was perfused with sterile PBS. The spleen and the inguinal, mesenteric, axillary, and submandibular lymph nodes were harvested for in vitro assays and FACS ${ }^{\circledR}$ analysis. In experiment 1 , the whole aorta was fixed in PBS with $1 \%$ formaldehyde and stained with oil red-O after removal of the adventitia under a macroscope. Specimens containing the root, arch, thoracic, and abdominal aorta were immersed for $3 \mathrm{~s}$ in $60 \%$ isopropanol and stained for $10 \mathrm{~min}$ in a saturated oil red-O solution. They were rinsed in wa-

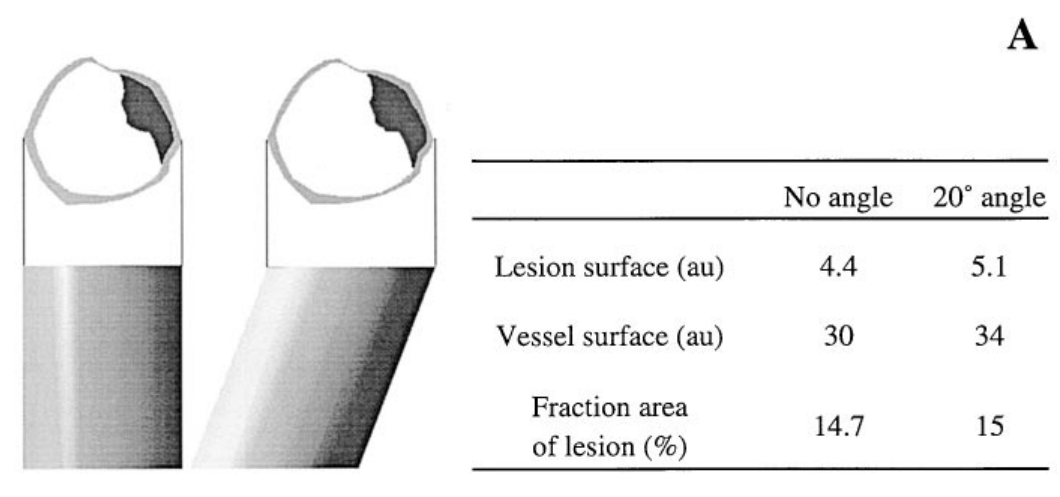

$$
r^{2}=0.88
$$

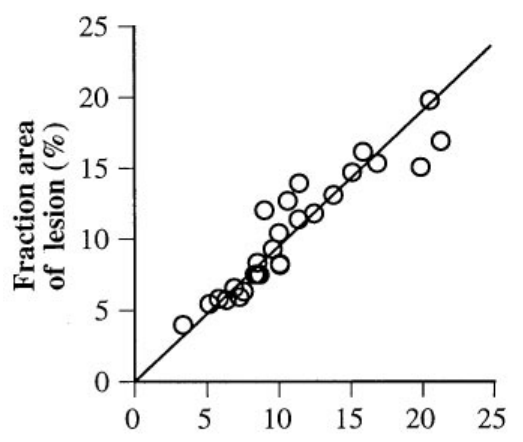

B

A

$$
\mathrm{r}^{2}=0.75
$$

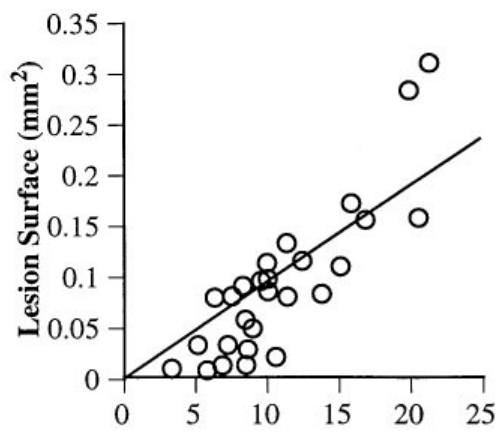

Volume Fraction (\%)

(Volume Lesion / Volume Vessel)
Figure 1. Effects of section angle on lesion estimates. (A) Computer simulation of an artery with an atherosclerotic lesion shows the effect of the section angle on the lesion estimate. Notice that the fraction area of lesion (lesion surface/vessel surface at cross-section) is relatively insensitive to angles at sectioning, whereas the absolute lesion surface is overestimated by $>15 \%$ at a tilting of only $20^{\circ}$. (B) Regression between the volume fraction of the lesion with both the lesion surface and the fraction area of lesion (surface area of the lesion/surface area of the vessel). 
ter and mounted en face on slides under coverslips within Kaiser's glycerol gelatin (Merck, Darmstadt, Germany). The cryosections were counterstained with hematoxylin.

In experiment 2, the root of the aorta was dissected under a macroscope and frozen in OCT embedding medium for serial cryosectioning covering $0.8 \mathrm{~mm}$ of the root. The first section was harvested when the first cusp became visible in the lumen of the aorta. Five sections of $10 \mu \mathrm{m}$ in thickness were harvested per slide and thus 18 slides per mouse were prepared. Sections at 0, 200, 400, 600, and $800 \mu \mathrm{m}$ distance from the cusps were stained with oil red-O, counterstained with hematoxylin, and mounted under coverslips.

Quantitation of atherosclerotic lesions. The oil red-O-stained en face specimens were analyzed at a magnification of 2.5. The image was captured on a microcomputer and a program developed in Quips language (Leica, Cambridge, UK) permitted a quantitation of the surface area of the lesion and the total surface area of the tissue sample. The ratio of these two surfaces provided the fraction area of the lesion. The oil red-O-stained cryosections were analyzed at a magnification of five using a similar program to quantify the cross-section surface area of the lesion and the cross-section surface area of the vessel. The fraction area of the lesion was calculated by dividing the surface of the lesion by the surface of the vessel. This allowed us to correct for errors caused by oblique sections that could otherwise lead to overestimation of the surface area occupied by a lesion (Fig. 1 $A$ ). The most important value to estimate is actually the volume fraction of the lesions. This can be calculated as the volume of the lesion divided by the volume of the vessel. Knowing the distance between the sections and the cross-section surface area of both the lesion and the vessel, it is possible to compute the volume [ $\Sigma$ (surface area $\times$ distance)] of both the vessel and of the lesion and finally the volume fraction. As shown in Fig. $1 \mathrm{~B}$, the fraction area of the lesion was strongly correlated to the volume fraction of the lesion $\left(r^{2}=0.88\right)$, whereas the surface of the lesion not normalized by the dimension of the vessel was less well correlated $\left(r^{2}=0.75\right)$.

Immunohistochemistry. Cryosections were processed for immunohistochemistry as described previously (8) with minor modifications. In brief, CD4 (1:50), CD8 (1:50), and I-Ab (1:25) antibodies (PharMingen, San Diego, CA) were applied to acetone-fixed cryosections. After a washing step, the second antibody (a biotinylated rabbit anti-rat immunoglobulin antibody) and $\mathrm{ABC}$ alkaline phosphatase kit (Vector Laboratories, Burlingame, CA) were used. The enzyme was revealed with $0.2 \mathrm{mg} / \mathrm{ml}$ naphtol AS.MX (Sigma Chemical Co., St. Louis, MO), $0.002 \mathrm{mg} / \mathrm{ml}$ dimethyl formamide (Merck, Darmstadt, Germany) in $0.1 \mathrm{M}$ Tris, $\mathrm{pH} 8.2,1 \mathrm{mg} / \mathrm{ml}$ Fast Red TR salt (Sigma), and $0.33 \mathrm{mg} / \mathrm{ml}$ levamisole (Sigma). Sections were counterstained with hematoxylin.

LDL preparations. Human LDL $(d=1.019-1.063 \mathrm{~g} / \mathrm{ml})$ was obtained under sterile conditions by ultracentrifugation of human plasma collected from 10 donors. Malondialdehyde-modified LDL (MDA-LDL) were produced as described previously $(2,21)$. In brief, MDA was generated by acidic reaction of malondialdehyde bis dimethylacetal tetramethoxypropane (Sigma) with $\mathrm{HCl}(4 \mathrm{M})$ for $10 \mathrm{~min}$ $37^{\circ} \mathrm{C}$. After neutralization of the MDA solution, $100 \mu \mathrm{l}$ of MDA $(0.5 \mathrm{M})$ was added to $1 \mathrm{mg}$ of LDL. After $3 \mathrm{~h}$ of incubation at $37^{\circ} \mathrm{C}$, free MDA was removed by running a PD10 Sephadex column (Pharmacia, Uppsala, Sweden). oxLDL was produced by an overnight oxidation with $5 \mathrm{mM} \mathrm{CuSO}_{4}$ as described previously (1). The degree of oxidation was evaluated by a spectrofluorometric analysis (excitation at $350 \mathrm{~nm}$ and emission at a wavelength of $433 \mathrm{~nm}$ ) as described by Steinbrecher (22). The fluorescent intensity of the oxLDL preparations was always $>0.5$ as compared with the fluorescent intensity of native $\mathrm{LDL}<0.2$.

ivIg and anti-ivIg antibodies in recipient mice. An ELISA was set up to quantify the titer of circulating levels of human ivIg in mouse sera. 96-well flat-bottomed plates (Corning Costar Corp., Cambridge, MA) were coated with mouse sera and incubated overnight at $4^{\circ} \mathrm{C}$. The plates were washed three times with PBS- $0.05 \%$ Tween, blocked with PBS-5\% BSA, and washed with PBS-Tween. An anti-human
Fc $\gamma$ antibody conjugated to alkaline phosphatase (Southern Biotechnology, Birmingham, AL) was added at 1:1,000 and the plates were incubated for $1 \mathrm{~h}$ at $37^{\circ} \mathrm{C}$ under gentle agitation. After PBS-Tween washes, $25 \mu \mathrm{l}$ of substrate solution was added (a $5 \mathrm{mg}$ tablet of $p$-nitrophenyl phosphate [Sigma] in $5 \mathrm{ml} 0.1 \mathrm{M} \mathrm{NaCl}, 5 \mathrm{mM} \mathrm{MgCl}$, $0.1 \mathrm{M}$ Tris- $\mathrm{HCl}$ ). Immunoreactivity was determined by absorbance at $405 \mathrm{~nm}$ using an automated plate reader (Labsystems Multiskan, Helsinki, Finland). Levels of remaining ivIg in mouse sera were calculated by subtracting the absorbance of controls without sera.

The levels of antibodies to ivIg in mouse sera were assessed by coating 96-well plates with $50 \mu \mathrm{l}$ ivIg $(10 \mu \mathrm{g} / \mathrm{ml})$. After an overnight incubation at $4{ }^{\circ} \mathrm{C}$ and washing and blocking steps, mouse sera were added at 1:10 dilutions and the plates were incubated for $1 \mathrm{~h}$ at $37^{\circ} \mathrm{C}$. After washing and blocking steps, the titer of anti-ivIg antibodies was revealed by using an anti-mouse antibody conjugated to alkaline phosphatase as described above. Titers of antibodies to ivIg were calculated by subtracting the absorbance of controls without serum.

Autoantibody titers to $n L D L, M D A-L D L$, and ox $L D L$. The titer of autoantibodies was measured by ELISA as described above. Plates were coated overnight with native LDL, MDA-LDL, and oxLDL at $10 \mu \mathrm{g} / \mathrm{ml}$. Mouse sera were added at 1:100 for the IgM titers and at 1:10 for IgG1 and IgG2a titers. Finally, alkaline phosphatase-conjugated detecting antibodies were plated at the following dilutions: anti-mouse IgM (Southern Biotechnology): 1:1,000; G1-6.5 antimouse IgG1 and R19-15 anti-mouse IgG2a (PharMingen): 1:250. The detection step was as described above. To check whether variations observed in the titer of specific immunoglobulins were due to variations of the overall concentration of immunoglobulin isotype, the titers of total IgG1 and IgG2a were measured using the following capture/detecting antibody pairs: anti-mouse IgG1 (Serotec, Oxford, UK)/HRP-conjugated anti-mouse IgG1 (Serotec); anti-mouse IgG2a (R12-4, PharMingen)/ALP-conjugated anti-mouse IgG2a (R19-15; PharMingen). The HRP-conjugated antibodies were revealed by adding one $5 \mathrm{mg}$ tablet of $o$-phenylenediamine dihydrochloride (Sigma) to $10 \mathrm{ml}$ of substrate buffer with $4 \mu \mathrm{H}_{2} \mathrm{O}_{2}$ and absorbance was determined at $450 \mathrm{~nm}$. As controls for autoantibodies, the antigen or the serum was omitted, while the controls for total IgG1 and IgG2a omitted the capture antibody or the serum. In all cases, titers of antibodies were calculated by subtracting the absorbance by values obtained in the controls.

Cell culture. Spleens and lymph nodes were processed separately but were pooled in each group of animals. Lymph node cells and spleen cells were prepared by meshing the tissues on $100-\mu \mathrm{m}$ nylon filters followed by a series of washing steps in DME with 5\% FBS

Table II. Effect of ivIg Treatment on Body Weight and Plasma Cholesterol

\begin{tabular}{lcc}
\hline \multicolumn{1}{c}{ Groups } & Weight \pm SEM & Cholesterol \pm SEM \\
\hline & $g$ & mmol/liter \\
Experiment 1 & & \\
ivIg[0-1] & $29.2 \pm 2.9$ & $14.0 \pm 1.2$ \\
HSA[0-1] & $32.0 \pm 2.9$ & $11.3 \pm 1.1$ \\
ivIg[0-2] & $30.2 \pm 1.3$ & $12.0 \pm 1.1$ \\
HSA[0-2] & $29.4 \pm 3.0$ & $12.7 \pm 1.1$ \\
Experiment 2 & & \\
ivIg[0-4] & $28.8 \pm 2.6$ & $15.7 \pm 1.4$ \\
HSA[0-4] & $31.0 \pm 2.4$ & $11.4 \pm 1.2$ \\
ivIg[2-4] & $31.2 \pm 1.9$ & $17.3 \pm 1.8$ \\
HSA[2-4] & $29.6 \pm 2.9$ & $11.4 \pm 1.5$ \\
ivIg[0/2-4] & $30.8 \pm 1.5$ & $14.5 \pm 1.6$ \\
HSA[0/2-4] & $30.8 \pm 2.4$ & $11.3 \pm 0.9$ \\
Untreated[0/0-4] & $28.5 \pm 2.9$ & $17.0 \pm 1.9$ \\
& &
\end{tabular}



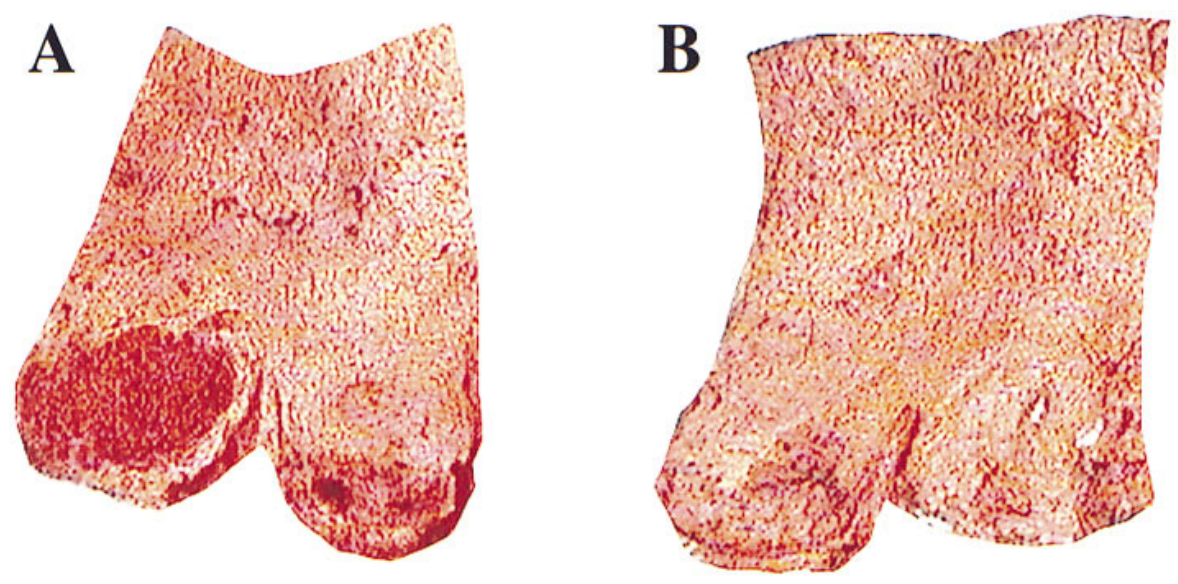

Figure 2. Effect of ivIg on fatty streak formation. apo E KO mice were injected with HSA or ivIg and then fed a Western diet for 2 mo (experiment 1). En face specimens from the aortic root were stained with oil red-O and photographed at a magnification of 2.5. ( $A$ ) HSA treatment. Notice large lesion in the left part of the root. $(B)$ ivIgtreated mouse. No large lesions are found.

(DME-5\%). Red blood cells were lysed in the spleen cell preparations with ACK lysing buffer $\left(0.15 \mathrm{M} \mathrm{NH}_{4} \mathrm{Cl}, 1 \mathrm{mM} \mathrm{KHCO}, 0.1 \mathrm{mM}\right.$ $\mathrm{Na}_{2}$ EDTA, pH 7.3). 300,000 cells/well were plated into 96-well flatbottomed plates in the presence of the following stimuli: Concanavalin A (Con A, $2.5 \mu \mathrm{g} / \mathrm{ml}$; Sigma), oxLDL and native LDL (3.125 and $6.25 \mu \mathrm{g} / \mathrm{ml})$, and ivIg and HSA $(20 \mathrm{mg} / \mathrm{ml})$. Each type of stimulation was performed in duplicate. The plates were incubated for $2 \mathrm{~d}$ at $37^{\circ} \mathrm{C}, 0.5 \% \mathrm{CO}_{2} .50 \mu \mathrm{l}$ of supernatant was removed from each well to check the production of IL-2 and IL-4 by a CTL-L2 bioassay and were replaced by $50 \mu \mathrm{l}$ of DME-5\% containing $1 \mu \mathrm{Ci}$ of $\left[{ }^{3} \mathrm{H}\right]$ thymidine. After an additional day of incubation, the cells were harvested and transferred to glass fiber filters (Wallac, Turku, Finland) using an Inotech (Wohlen, Switzerland) cell harvester. The filters were dried at $60^{\circ} \mathrm{C}$ for $1 \mathrm{~h}$, sealed in a sample bag with melt-on scintillor sheets (Wallac), and placed in a Wallac Microbeta $\beta$-counter. Results expressed as counts per minute reflect the incorporation of $\left[{ }^{3} \mathrm{H}\right]$ thymidine into DNA and thus the proliferation of the cells. For the CTLL2 assay, 5,000 CTL-L2 cells were added to the $50 \mu$ l of supernatant and $1 \mu \mathrm{Ci}$ of $\left[{ }^{3} \mathrm{H}\right]$ thymidine was added after $1 \mathrm{~d}$ of incubation. After $18 \mathrm{~h}$, the cells were harvested as described above.

FACS ${ }^{\circledR}$ analysis. A fraction of the cells prepared for cell culture was used for a FACS ${ }^{\circledast}$ analysis to check the different cells populations and their activation state. Cells were stained for $30 \mathrm{~min}$ at $4{ }^{\circ} \mathrm{C}$ using purified anti-CD3 and anti-CD25, biotin-conjugated anti-CD4 and anti-CD19, and FITC-conjugated anti-CD8 and anti-CD69 anti-

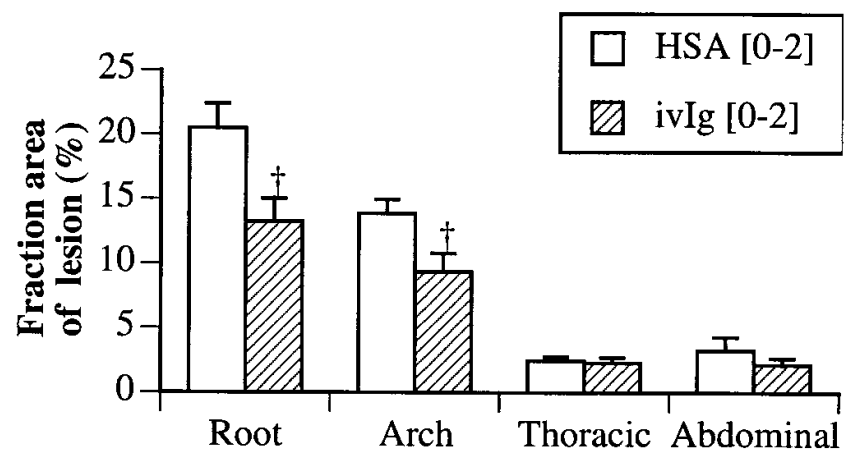

Figure 3. ivIg reduces fatty streak formation. apo E KO mice were injected with HSA or ivIg and then fed a Western diet for 2 mo (experiment 1). The lesion area (percentage of total surface area) was determined in oil red-O-stained en face specimens of the aorta. Lesion surface and vessel surface were determined using the Leica Quantimet image analysis system. Fraction area of lesion (percentage) is lesion surface/vessel surface. Means \pm SEM. 'Significantly different from HSA treatment, $P<0.01$. bodies (PharMingen). Cells were washed and analyzed with a FACSCalibur $^{\circledR}$ (Becton Dickinson, Mountain View, CA) flow cytometer.

Statistical analysis. Results are expressed as means \pm SEM. Data were analyzed by one-factor ANOVA using Statview 4.1 software (Abacus Concept Inc., Berkeley, CA). Differences between groups were considered significant if $P<0.05$. Regression coefficients were obtained by the least squares method.

\section{Results}

ivIg treatment. 7-8-wk-old apo E KO mice were injected intraperitoneally with $10 \mathrm{mg}$ human ivIg (Sandoglobulin ${ }^{\circledR}$ ) or HSA daily for five consecutive days and then fed an atherogenic diet for 2 or 4 mo. The injected ivIg was detectable in mice sera after 1 mo but the levels were close to background at 2 and 4 mo after treatment, indicating clearance from the plasma compartment with kinetics similar to that of endogenous Ig. A weak anti-human Ig reactivity could be detected and the elimination of ivIg was more rapid in mice treated with two ivIg injections than in those injected only once. This suggests that an antibody response may promote the elimination of ivIg. The ivIg treatment did not affect plasma cholesterol or body weight significantly compared with HSA-treated or untreated control mice (Table II).

Effect of ivIg on fatty streak formation. apo E KO mice were injected with ivIg or HSA over a 5-d period and then kept on a cholesterol-rich, Western diet for $8 \mathrm{wk}$ to induce fatty streak formation (23). Controls receiving HSA developed extensive lesions in the root and arch of the aorta, whereas

Table III. Effect of ivIg on the Inflammatory Cell Infiltrate of the Lesions

\begin{tabular}{lcc}
\hline & Untreated[0/0-4] & ivIg [0/2-4] \\
\hline $\mathrm{CD}^{+}$ & $6.7 \pm 1.5$ & $7.1 \pm 1.6$ \\
$\mathrm{CD}^{+}$ & $3.2 \pm 0.2$ & $2.7 \pm 0.6$ \\
$\mathrm{I}^{+} \mathrm{A}^{\mathrm{b}+}$ & $3.7 \pm 0.7$ & $3.5 \pm 0.6$ \\
\hline
\end{tabular}

Lesions of the aortic root were analyzed. Data were obtained by dividing the number of positively stained cells by all hematoxylin-stained cells inside the internal elastic lamina. Three random microscopic fields were analyzed at $\times 400$. 

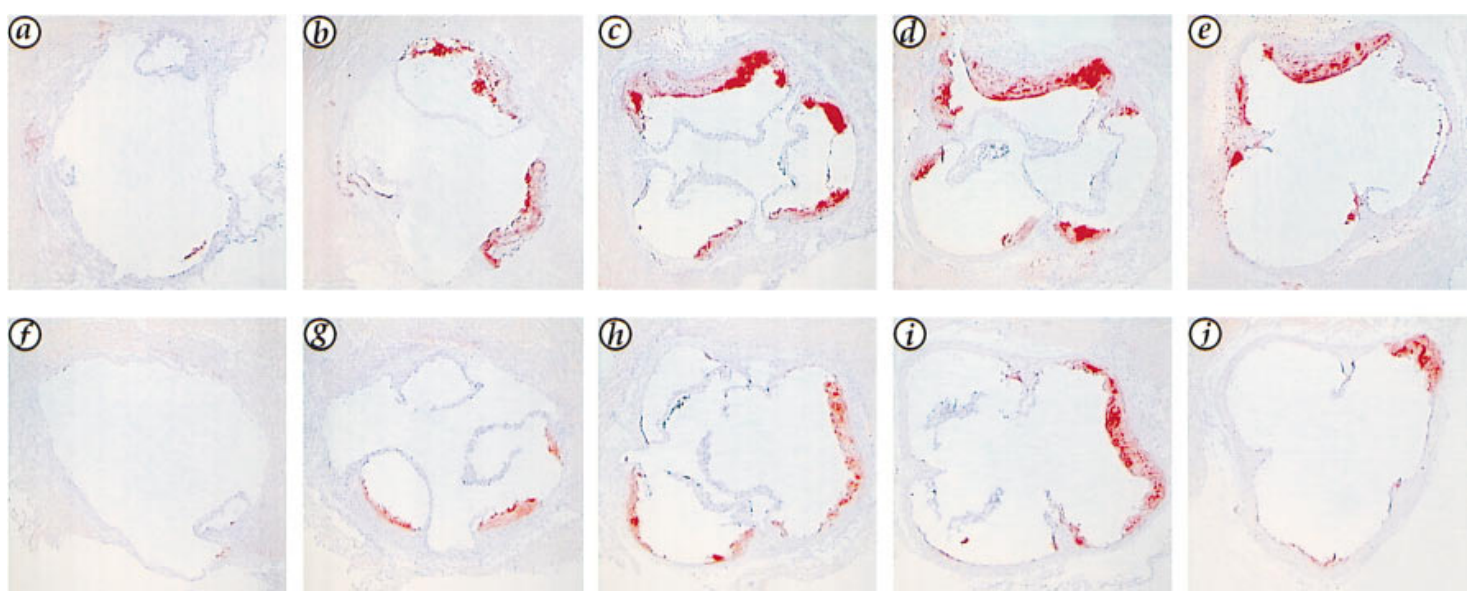

Figure 4. Effect of ivIg on the formation of fibrofatty plaques. apo E KO mice were fed a Western diet for 2 mo, injected with ivIg or HSA, and then continued on the diet for another 2 mo (experiment 2). The aortic root was cryosectioned and stained for lipids with oil red-O. Magnification, $\times 5$. $(a-e)$ Five consecutive sections from HSA-treated mice covering all the root of the aorta, taken every $200 \mu \mathrm{m}$ from the origin. $(f-j)$ Five consecutive sections from ivIg-treated mice. Lesions of ivIg-treated mice are smaller and cover a smaller fraction of the inner circumference of the aortic root than those of HSA-treated control mice.

smaller lesions were detected in the descending thoracic and abdominal parts of the aorta (Figs. 2 and 3). The surface area covered by fatty streak lesions was quantified in oil red-Ostained samples and specimens from ivIg-treated mice were compared with HSA-treated controls. In mice treated with ivIg, the fraction area of lesion was reduced by $35 \%$ in the aortic root and $32 \%$ in the arch (Figs. 2 and 3).

Effect of ivIg on atherosclerosis. In a second series of experiments, mice were kept on the Western diet for 4 mo to permit the formation of fibrofatty atherosclerotic plaques (23). ivIg and HSA injections were given either at the start of feeding, i.e., at $7 \mathrm{wk}$ of age, after $2 \mathrm{mo}$ on the diet, i.e., at $15 \mathrm{wk}$ of age, or both at 7 and 15 wk of age. An additional control group was left untreated and all mice were killed at $22 \mathrm{wk}$ of age (i.e., after 4 mo on the diet).

This treatment resulted in extensive lesion formation in both HSA-treated and untreated mice (Fig. 4). Both these groups exhibited lesion formation covering $12-15 \%$ of the cross-sectioned aortic root (Fig. 5). Mice treated with ivIg at 0 and 2 mo of diet (the ivIg[0/2-4] group) or only at 2 mo (ivIg[24]) showed a $50 \%$ reduction of lesion formation, with only $6-8 \%$ of the cross-section area covered by lesions (Figs. 4 and 5). In all groups, lesions were fibrofatty plaques with lipid-rich core regions covered by fibrous cap with smooth muscle cells (Figs. 4 and 6). The cellular composition of the lesions did not differ significantly between the groups. In particular, the inflammatory cell infiltrate as assessed by the number of $\mathrm{CD} 4^{+}, \mathrm{CD}^{+}$, or $\mathrm{I}_{-} \mathrm{A}^{\mathrm{b}+}$ cells divided by the number of hematoxylin-stained cells was not significantly different between the different groups (Fig. 6, Table III, and data not shown). In contrast, ivIg injections at the beginning of the diet treatment did not confer protection against atherosclerosis (Fig. 5).

Effect of ivIg on immune responses. ivIg treatment did not affect the relative proportions of $\mathrm{CD}^{+}, \mathrm{CD}^{+}$, or $\mathrm{CD} 8^{+} \mathrm{T}$ cells, CD $19^{+} \mathrm{B}$ cells, or the proportion of activated cells expressing CD25 or CD69, as determined by FACS ${ }^{\circledR}$ analysis of spleen and lymph node cell suspensions (data not shown). However, spleen and lymph node cells of ivIg-treated apo E
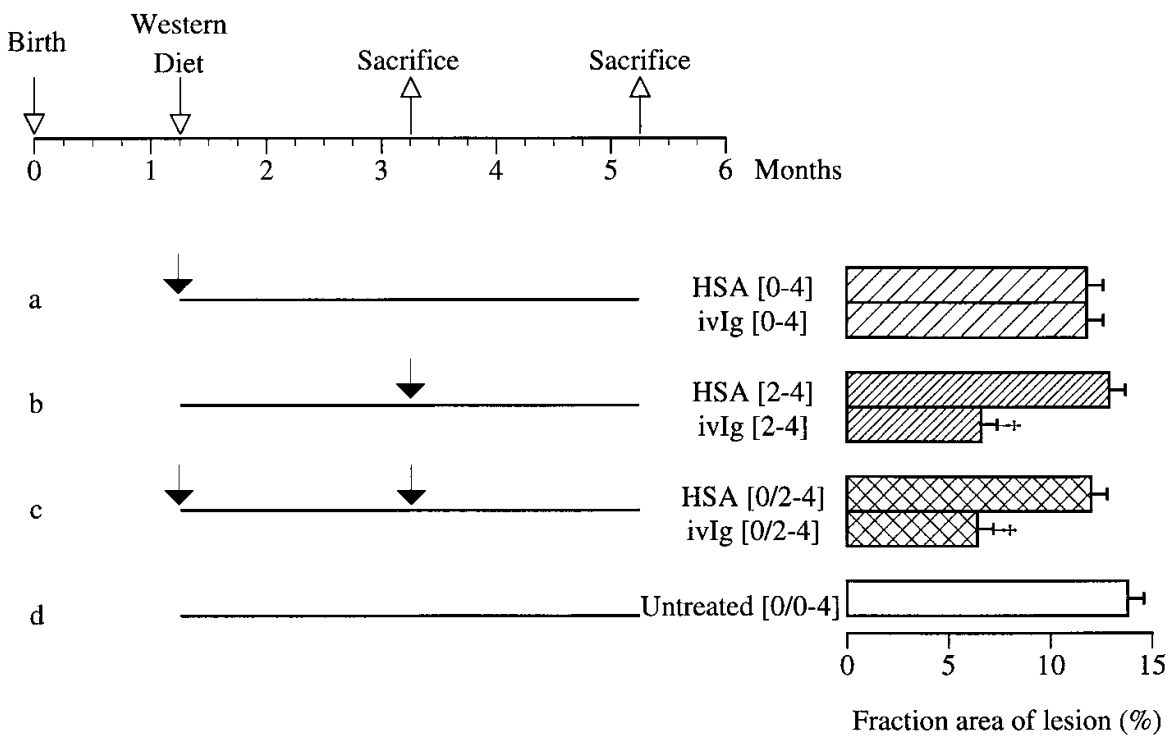

Figure 5. ivIg treatment inhibits formation of fibrofatty plaques. apo E KO mice were fed a Western diet for 4 mo (experiment 2) and were injected with HSA or ivIg immediately before the start of diet treatment $(a)$, after 2 mo on the diet $(b)$, or both at 0 and 2 mo $(c)$. A fourth group of mice $(d)$ received the diet but no injections. Lesion surface and vessel surface were determined using the Leica Quantimet image analysis system. Fraction area of lesion (lesion surface/vessel surface) was measured on cryosections from the aortic root. Means \pm SEM. $\dagger$ Significantly different from HSA-treated group, $P<0.01$. 

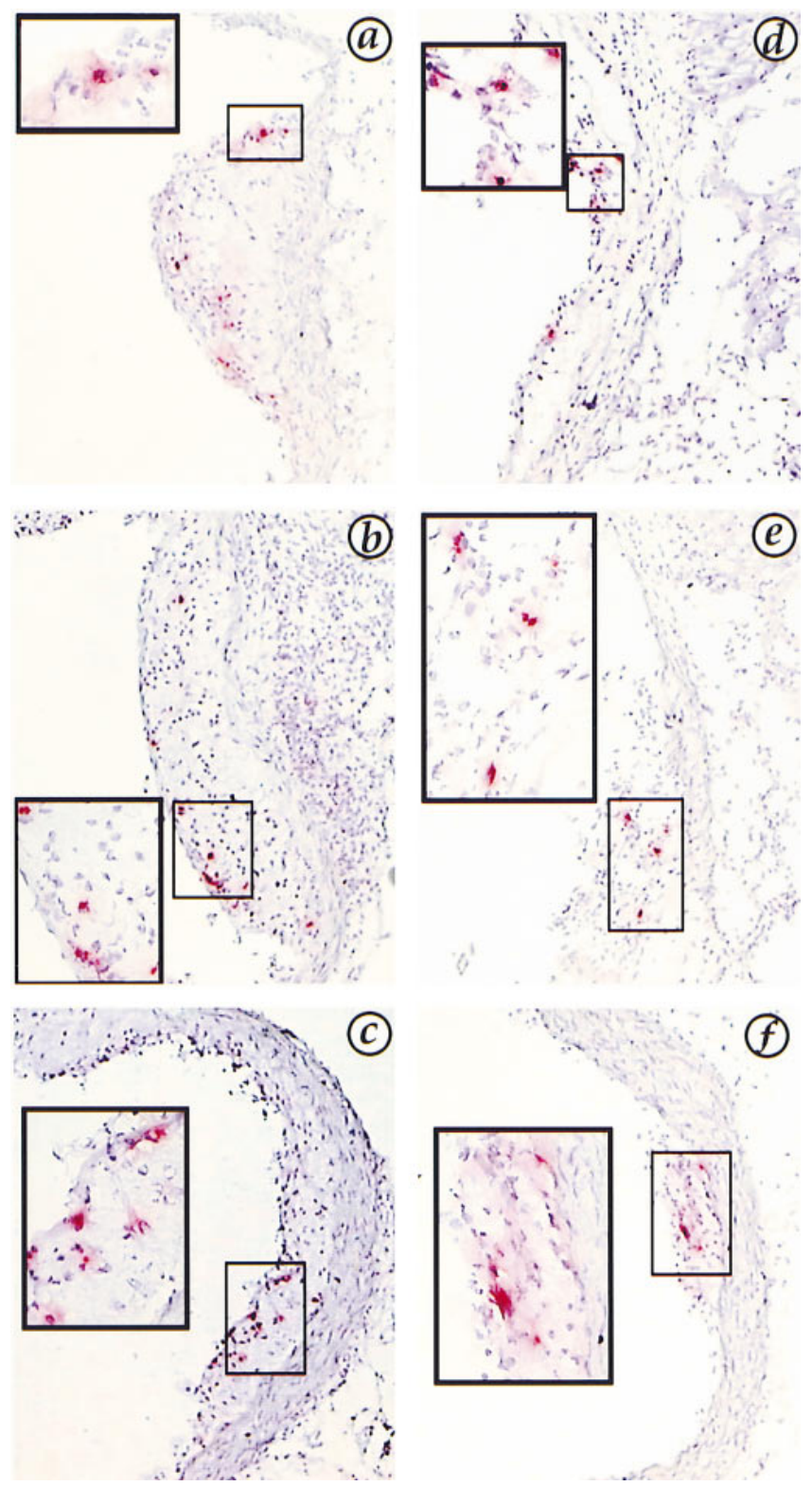

Figure 6. Inflammatory infiltrate is not modified by ivIg treatment. $\mathrm{CD}^{+}(a$ and $d), \mathrm{CD}^{+}\left(b\right.$ and $e$ ), and $\mathrm{I}-\mathrm{A}^{\mathrm{b}+}(c$ and $f$ ) cells infiltrating in the atherosclerotic lesions of control and ivIg-treated mice were immunostained ( $a-c$, control Untreated[0/0-4]; $d-f$, ivIg[0/2-4]).

KO mice exhibited a lower basal proliferation rate than those of HSA-treated or untreated apo E KO mice (Figs. 7 and 8). T cells of ivIg-treated mice were able to respond to Con A by proliferation, indicating that they were anergized rather than eliminated (Figs. 7 and 8). This was supported by the finding that addition of ivIg to spleen cells from control mice reduced $\mathrm{T}$ cell proliferation in response to Con A. The data obtained on the proliferation were corroborated by IL-2/IL-4 production assays (data not shown).

IgM antibodies to oxLDL were significantly reduced 2 mo after ivIg treatment, implying that the B cell response was also hampered by the treatment (Fig. 9). This effect was no longer discernible after 4 mo (data not shown). No effect were observed on IgG (Fig. 9), IgG1, or IgG2a antibodies to oxLDL (data not shown).

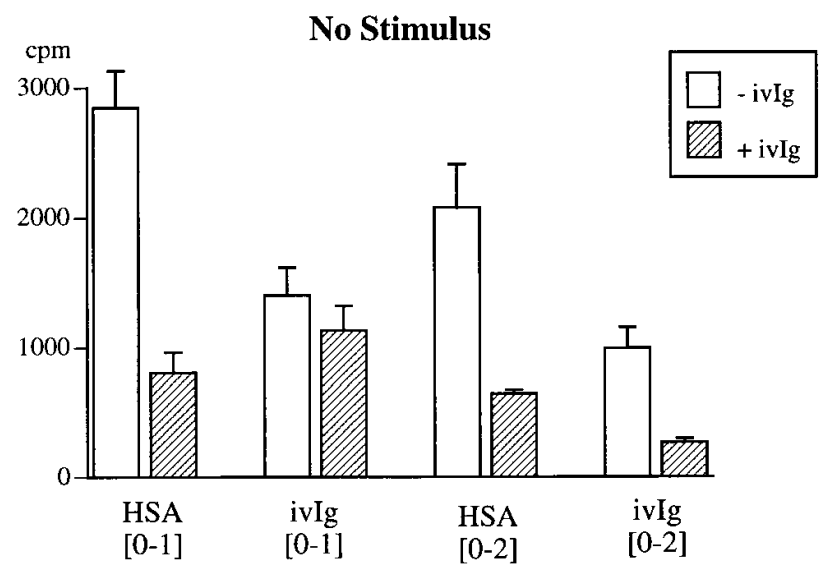

$\operatorname{ConA} 2.5 \mu \mathrm{g} / \mathrm{ml}$

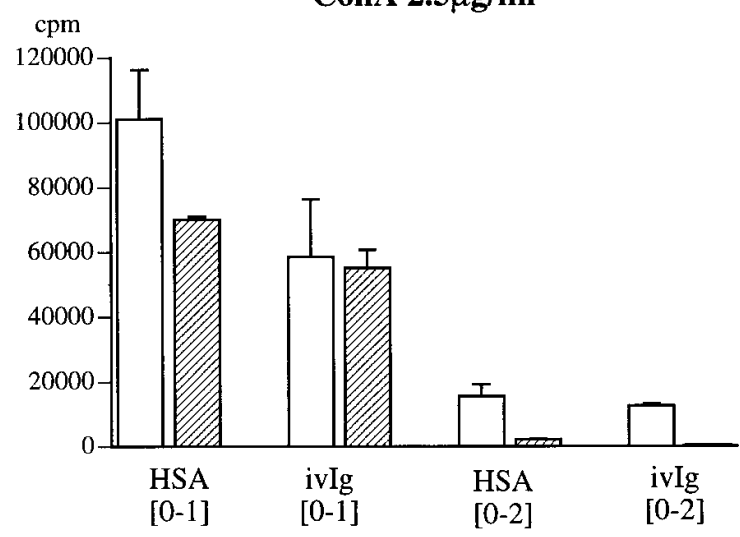

Figure 7. ivIg inhibits $\mathrm{T}$ cell proliferation in vivo and in vitro (experiment 1). apo E KO mice were injected with HSA or ivIg and fed a Western diet for 1 [0-1] or $2[0-2]$ mo. The basal and Con A-induced proliferation $\left(\left[{ }^{3} \mathrm{H}\right]\right.$ thymidine incorporation, $\left.\mathrm{cpm}\right)$ was analyzed on lymph node cell suspensions. Both basal (No Stimulus) and Con A-induced proliferation (Con $A$ ) were reduced in ivIg-treated mice both at 1 and 2 mo after injection. Addition of ivIg to cultures inhibited basal and Con A-induced proliferation also in cells from HSA-treated mice. Means \pm SEM.

\section{Discussion}

This study shows that ivIg treatment inhibits atherosclerosis in cholesterol-fed apo E KO mice. Both the development of fatty streaks and the progression to fibrofatty atherosclerotic plaques could be inhibited by this treatment. This obviously suggest that similar ivIg-modulated mechanisms operate in both stages of the disease.

To reduce fatty streaks, it was sufficient to inject ivIg once at the start of treatment, whereas protection against atherosclerotic plaques required ivIg to be administered after 2 mo on the atherogenic diet. Since ivIg was cleared from the circulation after 1-2 mo, these data suggest that protection depends on the presence of the infused immunoglobulins in the animal. The lack of protection against atherosclerosis by the fatty streak-preventing protocol (i.e., ivIg injections at the beginning of treatment) suggests that prevention of fatty streaks may not be sufficient to prevent subsequent formation of atherosclerotic plaques. This may reflect a capacity of ivIg to inactivate but not eliminate atherogenic factors. If this is the case, 

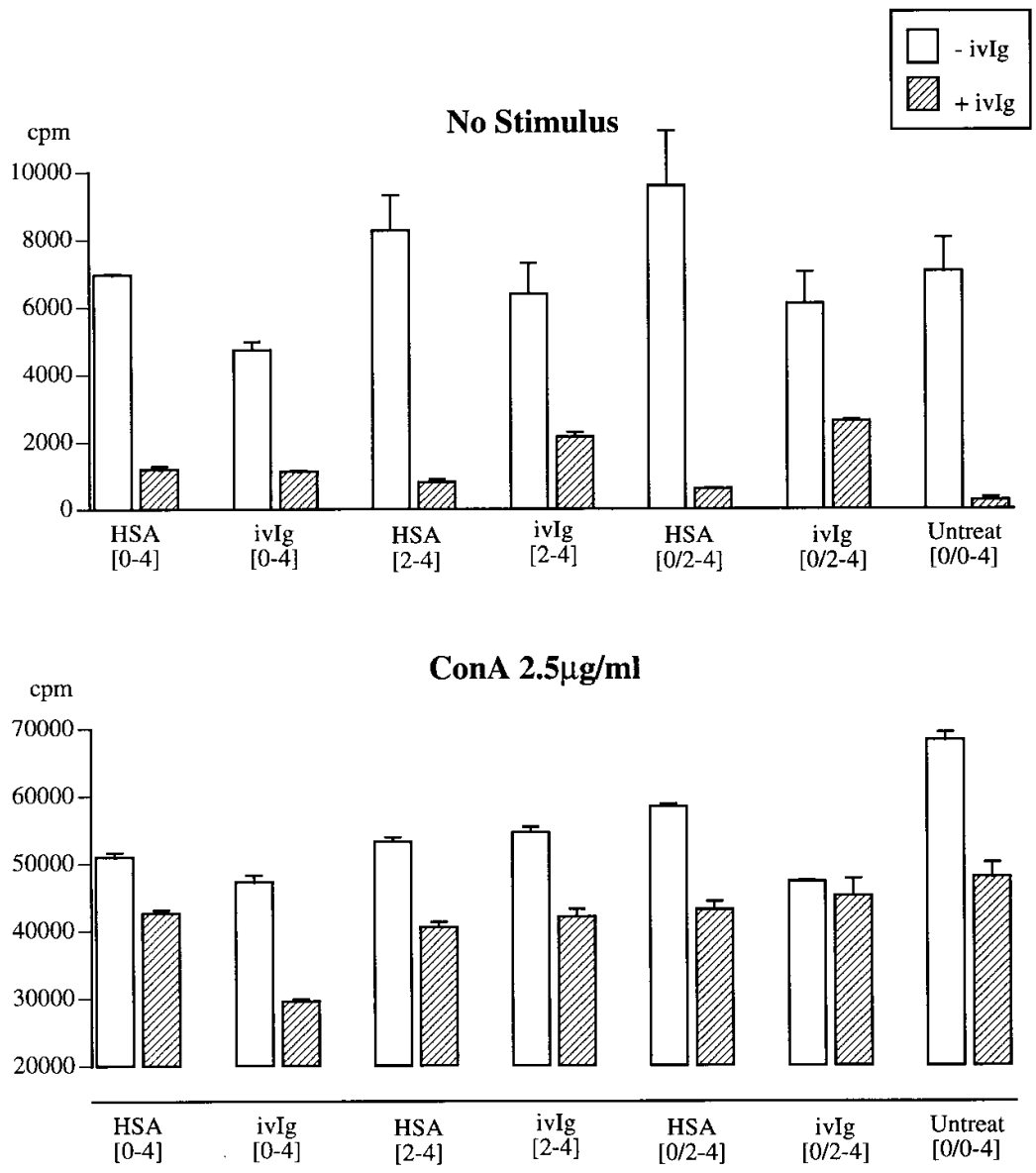

\begin{abstract}
Figure 8. ivIg inhibits T cell proliferation in vivo and in vitro (experiment 2). apo $\mathrm{E} \mathrm{KO}$ mice were injected with HSA or ivIg and kept on a Western diet for 4 mo. Compared with HSA-treated mice, the proliferation $\left(\left[{ }^{3} \mathrm{H}\right]\right.$ thymidine incorporation, cpm) under basal conditions (No Stimulus) of lymph node cells was reduced in mice treated with ivIg at the start of the experiment [0-4], mice given ivIg after 2 mo of diet [2-4], and mice injected with ivIg at the start and after 2 mo [0/2-4]. Con A-induced proliferation was inhibited in groups receiving ivIg at 0 and 2 mo or at 2 mo only. Addition of ivIg to cell cultures inhibited proliferation in all groups except ivIg[0/2-4]. Means \pm SEM.
\end{abstract}

such factors would presumably be reactivated when ivIg disappears from the circulation. Alternatively, different factors present in the ivIg preparation act in the fatty streak phase and the phase of plaque growth.

The precise atheroprotective mechanism(s) conferred by ivIg treatment have not been identified but it is interesting that the atheroprotective effect was paralleled by effects on $\mathrm{T}$ and B cells. T cells of ivIg-treated mice exhibited a lower basal proliferation rate but could be activated to proliferate by addition of the polyclonal mitogen, Con A. This suggests that ivIg inhibits T cell activation. Such an interpretation was supported by the observation that in vitro treatment of spleen cell cultures with ivIg blocked $\mathrm{T}$ cell activation. If $\mathrm{T}$ cells infiltrating fatty streaks and atherosclerotic plaques are also anergized, this would reduce immune activation in the artery. Since most plaque $\mathrm{T}$ cells are proinflammatory Th1 effector cells, a conceivable consequence is reduced macrophage activation. The recent finding that elimination of Th1 signaling by targeted disruption of the interferon- $\gamma$ receptor gene inhibits atherosclerosis in apo E KO mice by $60 \%$ (12) is in agreement with such an interpretation. Interestingly, ivIg preferentially downregulates $\mathrm{T}$ cell cytokine secretion, whereas monokine production is less affected (24).

In addition to its effect on $\mathrm{T}$ cells, ivIg also reduced autoantibody titers to oxLDL species. Since a significant reduction was found for IgM but not IgG antibody classes, this effect was probably exerted directly on the B cell. A drop in the titer of autoantibodies after administration of ivIg has been reported previously in several autoimmune manifestations (14). Re- cently, the B cell/humoral immunity system was shown to play a major role in the pathogenesis of transplant arteriopathy (25) but its role in atherosclerosis has remained obscure. Few B cells are found in developing atherosclerotic plaques but advanced plaques of fat-fed rabbits were reported to contain significant amounts of Ig-secreting plasma cells (26).

Anti-oxLDL antibody titers appear to reflect disease activity but the pathogenic mechanisms of these antibodies remain unclear. While IgM antibodies do not mediate rapid antigen elimination via Fc receptors, their interaction with oxLDL in the arterial intima could initiate complement activation. This may secondarily lead to cell death, proteolysis, release of chemotactic agents, and local inflammation. Therefore, a reduction of the IgM anti-oxLDL titer might dampen vascular inflammation.

In addition to the immunomodulatory effects of ivIg, the possibility that it confers protection against atherosclerosis by transfer of specific antibodies remains an exciting scenario. Microorganisms have been implicated recently in the pathogenesis of atherosclerosis and there is strong epidemiological evidence for an association between Chlamydia pneumoniae and cardiovascular disease in humans. The ivIg preparations contain thousands of different antibody specificities, which can neutralize a large series of pathogens. However, it is unlikely that more than a small proportion of these microorganisms would affect vascular disease in both humans and rodents. However, antibodies directed against several cell surface molecules of relevance in immunomodulation have also been identified in ivIg preparations (27-30). In addition, soluble 

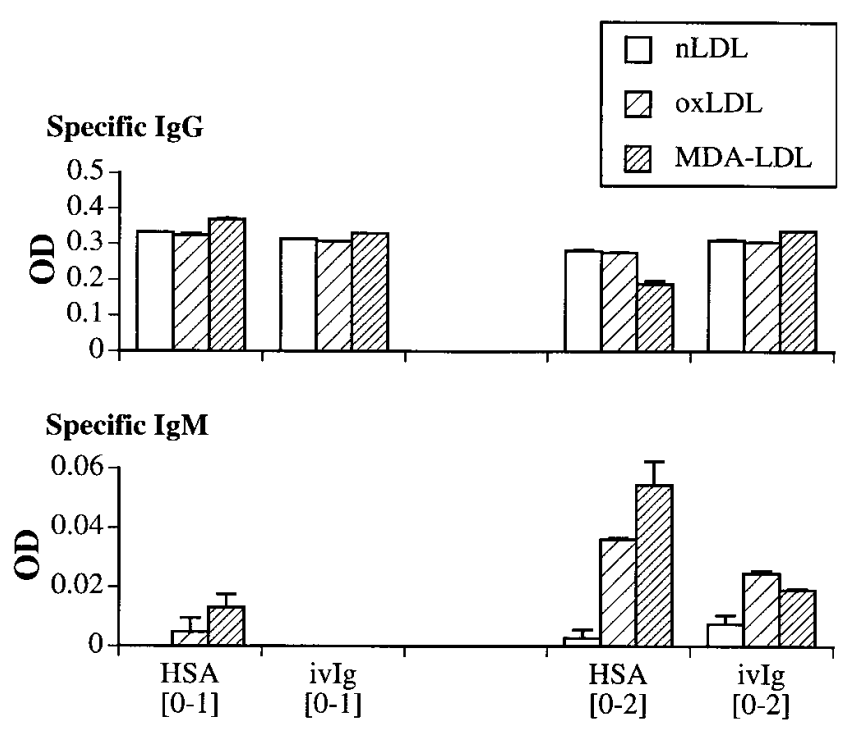

Figure 9. ivIg reduces IgM antibodies to modified LDL. Sera were collected from apo E KO mice injected with HSA or ivIg and then fed a Western diet for 1 [0-1] or 2 [0-2] mo. IgM and IgG autoantibodies to native LDL (nLDL), $\mathrm{Cu}^{2+}$-oxLDL (oxLDL), and MDA-LDL were detected by ELISA. ivIg treatment significantly reduced IgM antibodies to oxLDL and MDA-LDL. Means \pm SEM.

forms of CD4, CD8, and class I and class II molecules have been identified in ivIg $(31,32)$. Therefore, a fractionation of ivIg, and/or the use of specific antibodies in experimental models of atherosclerosis, should shed light on the role of specific antibodies in the atheroprotective action of ivIg.

In conclusion, we have shown that treatment of atherosclerosis-prone apo E KO mice with five injections of ivIg protects against fatty streak development over a 2-mo period of cholesterol treatment and that a similar protocol extended over a 4-mo period inhibits the formation of fibrofatty plaques in these mice. ivIg treatment was associated with anergization of T cells and reduction of $\operatorname{IgM}$ anti-oxLDL antibodies, but the precise mechanism by which ivIg confers protection against atherosclerosis remains unclear. However, the current results show, for the first time, that treatment by immunomodulation inhibits atherogenesis. The ivIg treatment protocol presented here is unlikely to be useful in preventing cardiovascular disease in humans, but the results are encouraging for investigators exploring immune-based therapy as a way to treat atherosclerosis.

\section{Acknowledgments}

We thank Ingrid Törnberg, Renée Langagne, Inger Bodin, and Anita Larsson for excellent technical assistance.

This work was supported by the Swedish Medical Research Council (Project 6816) and Heart-Lung Foundation, the Johnson and Wallenberg Foundations, King Gustaf V 80th Anniversary Fund, and the AFA Research Fund. A. Nicoletti was the recipient of a Marie Curie postdoctoral research fellowship from the European Union.

\section{References}

1. Stemme, S., B. Faber, J. Holm, O. Wiklund, J.L. Witzum, and G.K. Hansson. 1995. T lymphocytes from human atherosclerotic plaques recognize oxidized low density lipoprotein. Proc. Natl. Acad. Sci. USA. 92:3893-3897.

2. Palinski, W., M.E. Rosenfeld, S. Yla-Herttuala, G.C. Gurtner, S.S. Socher, S.W. Butler, S. Parthasarathy, T.E. Carew, D. Steinberg, and J.L. Witz- tum. 1989. Low density lipoprotein undergoes oxidative modification in vivo. Proc. Natl. Acad. Sci. USA. 86:1372-1376.

3. Ylä-Herttuala, S., W. Palinski, M.E. Rosenfeld, S. Parthasarathy, T.E. Carew, S. Butler, J.L. Witztum, and D. Steinberg. 1989. Evidence for the presence of oxidatively modified low density lipoprotein in atherosclerotic lesions of rabbit and man. J. Clin. Invest. 84:1086-1095.

4. Seifert, P.S., and G.K. Hansson. 1989. Complement receptors and regulatory proteins in human atherosclerotic lesions. Arteriosclerosis. 9:802-811.

5. Seifert, P.S., F. Hugo, G.K. Hansson, and S. Bhakdi. 1989. Prelesional complement activation in experimental atherosclerosis: terminal C5b-9 complement deposition coincides with cholesterol accumulation in the aortic intima of hypercholesterolemic rabbits. Lab. Invest. 60:747-754.

6. Salonen, J.T., S. Ylä-Herttuala, R. Yamamoto, S. Butler, H. Korpela, R. Salonen, K. Nyyssänen, W. Palinski, and J.L. Witztum. 1992. Autoantibody against oxidised LDL and progression of carotid atherosclerosis. Lancet. 339: 883-887.

7. Plump, A.S., J.D. Smith, T. Hayek, K. Aalto-Setala, A. Walsh, J.G. Verstuyft, E.M. Rubin, and J.L. Breslow. 1992. Severe hypercholesterolemia and atherosclerosis in apolipoprotein E-deficient mice created by homologous recombination in ES cells. Cell. 71:343-353.

8. Zhou, X., S. Stemme, and G.K. Hansson. 1996. Evidence for a local immune response in atherosclerosis. CD4+ T cells infiltrate lesions of apolipoprotein-E-deficient mice. Am. J. Pathol. 149:359-366.

9. Palinski, W., V.A. Ord, A.S. Plump, J.L. Breslow, D. Steinberg, and J.L. Witztum. 1994. ApoE-deficient mice are a model of lipoprotein oxidation in atherogenesis. Demonstration of oxidation-specific epitopes in lesions and high titers of autoantibodies to malondialdehyde-lysine in serum. Arterioscler. Thromb. 14:605-616.

10. Smith, J.D., E. Trogan, M. Ginsberg, C. Grigaux, J. Tian, and M. Miyata. 1995. Decreased atherosclerosis in mice deficient in both macrophage colony-stimulating factor (op) and apolipoprotein E. Proc. Natl. Acad. Sci. USA. 92:8264-8268.

11. Dansky, H.M., S.A. Charlton, M.M. Harper, and J.D. Smith. 1997. T and B lymphocytes play a minor role in atherosclerosis plaque formation in the apolipoprotein E-deficient mouse. Proc. Natl. Acad. Sci. USA. 94:4642-4646.

12. Gupta, S., A.M. Pablo, X.C. Jiang, N. Wang, and C. Schindler. 1997. IFN- $\gamma$ potentiates atherosclerosis in apo E knock-out mice. J. Clin. Invest. 99: 2752-2761.

13. Dwyer, J.M. 1992. Manipulating the immune system with immune globulin. N. Engl. J. Med. 326:107-116.

14. Kaveri, S.V., G. Dietrich, V. Hurez, and M.D. Kazatchkine. 1991. Intravenous immunoglobulins (IVIg) in the treatment of autoimmune diseases. Clin. Exp. Immunol. 86:192-198.

15. Kazatchkine, M.D., G. Dietrich, V. Hurez, N. Ronda, B. Bellon, F. Rossi, and S.V. Kaveri. 1994. V region-mediated selection of autoreactive repertoires by intravenous immunoglobulin (i.v.Ig). Immunol. Rev. 139:79-107.

16. Rossi, F., B. Bellon, M.C. Vial, P. Druet, and M.D. Kazatchkine. 1991. Beneficial effect of human therapeutic intravenous immunoglobulins (IVIg) in mercuric-chloride-induced autoimmune disease of Brown-Norway rats. Clin. Exp. Immunol. 84:129-133.

17. Forsgren, S., A. Andersson, V. Hillorn, A. Soderstrom, and D. Holmberg. 1991. Immunoglobulin-mediated prevention of autoimmune diabetes in the non-obese diabetic (NOD) mouse. Scand. J. Immunol. 34:445-451.

18. Hentati, B., M.N. Sato, B. Payelle-Brogard, S. Avrameas, and T. Ternynck. 1994. Beneficial effect of polyclonal immunoglobulins from malariainfected $\mathrm{BALB} / \mathrm{c}$ mice on the lupus-like syndrome of $(\mathrm{NZB} \times \mathrm{NZW}) \mathrm{F}_{1}$ mice. Eur. J. Immunol. 24:8-15.

19. Saoudi, A., V. Hurez, Y. de Kozak, J. Kuhn, S.V. Kaveri, M.D. Kazatchkine, P. Druet, and B. Bellon. 1993. Human immunoglobulin preparations for intravenous use prevent experimental autoimmune uveoretinitis. Int. Immunol. 5:1559-1567.

20. Piedrahita, J.A., S.H. Zhang, J.R. Hagaman, P.M. Oliver, and N Maeda. 1992. Generation of mice carrying a mutant apolipoprotein E gene inactivated by gene targeting in embryonic stem cells. Proc. Natl. Acad. Sci. USA. 89:4471-4475.

21. Palinski, W., S. Ylä-Herttuala, M.E. Rosenfeld, S.W. Butler, S.A. Socher, S. Parthasarathy, L.K. Curtiss, and J.L. Witztum. 1990. Antisera and monoclonal antibodies specific for epitopes generated during oxidative modification of low density lipoprotein. Arteriosclerosis. 10:325-335.

22. Steinbrecher, U.P. 1987. Oxidation of human low density lipoprotein results in derivatization of lysine residues of apolipoprotein B by lipid peroxide decomposition products. J. Biol. Chem. 262:3603-3608.

23. Nakashima, Y., A.S. Plump, E.W. Raines, J.L. Breslow, and R. Ross 1994. ApoE-deficient mice develop lesions of all phases of atherosclerosis throughout the arterial tree. Arterioscler. Thromb. 14:133-140.

24. Andersson, U., L. Björk, U. Skansén-Saphir, and J. Andersson. 1994. Pooled human IgG modulates cytokine production in lymphocytes and monocytes. Immunol. Rev. 139:21-42.

25. Shi, C., W.S. Lee, Q. He, D. Zhang, D.L. Fletcher, Jr., J.B. Newell, and E. Haber. 1996. Immunologic basis of transplant-associated arteriosclerosis. Proc. Natl. Acad. Sci. USA. 93:4051-4056.

26. Sohma, Y., H. Sasano, R. Shiga, S. Saeki, T. Suzuki, H. Nagura, M. Nose, and T. Yamamoto. 1995. Accumulation of plasma cells in atherosclerotic 
lesions of Watanabe heritable hyperlipidemic rabbits. Proc. Natl. Acad. Sci. USA. 92:4937-4941.

27. Hurez, V., S.V. Kaveri, B.A. Mouhou, G. Dietrich, J.C. Mani, D. Klatzmann, and M.D. Kazatchkine. 1994. Anti-CD4 activity of normal human immunoglobulins $G$ for therapeutic use (intravenous immunoglobulin, IVIg). Therap. Immunol. 1:269-278.

28. Kaveri, S., T. Vassilev, V. Hurez, R. Lengagne, S. Cot, P. Pouletty, and D. Glotz. 1996. Antibodies to a conserved region of HLA class I molecules, capable of modulating CD8 T cell-mediated function, are present in pooled normal immunoglobulin for therapeutic use (IVIg). J. Clin. Invest. 97:865-869.

29. Takei, S., Y. Arora, and S.M. Walker. 1993. Intravenous immunoglobulin contains specific antibodies inhibitory to activation of $\mathrm{T}$ cells by staphylococ- cal toxin superantigens. J. Clin. Invest. 91:602-607.

30. Vassilev, T., C. Gelin, S.V. Kaveri, M.T. Zilber, L. Boumsell, and M.D. Kazatchkine. 1993. Antibodies to the CD5 molecule in normal human immunoglobulins for therapeutic use (intravenous immunoglobulins, IVIg). Clin. Exp. Immunol. 92:369-372.

31. Lam, L., C.F. Whitsett, J.M. McNicholl, T.W. Hodge, and J. Hooper. 1993. Immunologically active proteins in intravenous immunoglobulin. Lancet. 342:678.

32. Blasczyk, R., U. Westhoff, and H. Grossewilde. 1993. Soluble CD4, CD8, and HLA molecules in commercial immunoglobulin preparations. Lancet. 341:789-790. 